9. Clark, D. A. Clark, D. B. \& Oberbauer, S. F. J. Geophys. Res. 118, 1-12 (2013).

10.Silva, L. C. R. \& Anand, M. Glob. Ecol. Biogeogr. 22, 83-92 (2013).

11.Donohue, R. J., McVicar, T. R. \& Roderick, M. L. Glob. Change Biol. 15, 1025-1039 (2009)

12.Baldocchi, D. Aust. J. Bot. 56, 1-26 (2008)

13.Wong, S. C., Cowan, I. R. \& Farquhar, G. D. Plant Physiol. 78, 821-825 (1985).
14.Drake, B. G., Gonzàlez-Meler, M. A. \& Long, S. P. Annu. Rev. Plant Physiol. Plant Mol. Biol. 28, 609-639 (1996).

15.Ainsworth, E. A. \& Rogers, A. Plant Cell Environ. 30, 258-270 (2007).

16. Barton C. V. M. et al. Glob. Change Biol. 18, 585-595 (2012)

17.De Kauwe, M. G. et al. Glob. Change Biol. 19, 1759-1779 (2013).

\title{
A three-state balancing act
}

\begin{abstract}
How do pathogens survive temperature variations? At a molecular level, one bacterial species seems to regulate gene expression in response to temperature through structural equilibria in corresponding RNA sequences. SEE LETTER P.355
\end{abstract}

\section{RONALD MICURA}

$\mathrm{I}$ n bacteria, many messenger RNA molecules carry a regulatory segment called a riboswitch. Specific binding of small ligand molecules, such as adenine, to this segment determine whether the riboswitch mRNA will be translated into a protein ${ }^{1-4}$. On page 355 of this issue, Reining et al. ${ }^{5}$ show that regulation of gene expression through such 'riboswitching' is coupled to temperature sensing. The authors investigate the adenine-sensitive riboswitch from the pathogenic bacterium Vibrio vulnificus ${ }^{6}$, and demonstrate that efficient RNA regulation at different temperatures - those of the bacterium's marine habitat and its human host - requires a change in the riboswitch's structural behaviour from a twostate pattern to a three-state one.*

A typical riboswitch consists of two domains at the $5^{\prime}$ end of the mRNA: a ligand-binding aptamer and an adjoining expression platform, which can have one of two mutually exclusive structures depending on whether the aptamer is in the ligand-bound or ligand-unbound state. The structural change in the expression platform signals that gene expression should be turned on or off.

During gene transcription, a polymerase enzyme synthesizes first the aptamer and then the expression platform ${ }^{7}$. The sequential release of riboswitch domains from the polymerase is especially meaningful for transcription-controlling riboswitches, which act under kinetic control. To direct the folding of the expression platform, the aptamer domain of the growing RNA chain must bind rapidly to its ligand, which requires high ligand concentrations $^{8}$; otherwise, the resulting fulllength mRNA becomes trapped in a default fold that cannot respond to the ligand ${ }^{9}$. In

*This article and the paper under discussion ${ }^{5}$ were published online on 10 July 2013. transcription-controlling riboswitches, the two mutually exclusive structures are generally referred to as terminator and antiterminator folds, causing cessation of polymerase respectively.

Bacterial transcription is tightly coupled to translation. In translation-controlling riboswitches, the molecular mechanism relies on either sequestration or liberation of the Shine-Dalgarno sequence - the mRNA site that binds to cellular organelles known as ribosomes to initiate translation. In contrast to transcription-controlling riboswitches, most translation-controlling riboswitches quently, ligand-dependent control of translation is maintained even for a full-length mRNA. For these riboswitches, therefore, two states (ligand-bound and -unbound) seem sufficient to turn translation on and off.

Reining and colleagues have found that, for robust functioning, their translation-controlling adenine-sensing riboswitch must occur in three structural states. The authors investigated the full-length (more than 100-nucleotide) riboswitch domain at single-nucleotide resolution. They also determined a complete set of thermodynamic and kinetic parameters for folding and ligand-binding of this RNA, under conditions that involved varying the concentrations of RNA, magnesium ions (a factor mediating structure formation) and adenine, as well as, importantly, temperature.

The researchers find that a ligand-free (apo) form of the riboswitch exists in a pre-equilibrium of two structurally distinct aptamer folds (Fig. 1). One of the structures (apoA) can bind to the ligand, exhibiting a structure that resembles a third structural state - the adenine-bound holo form. The other structure (apoB) adopts a different fold and cannot interact with the ligand. But why does activity and continuation of mRNA synthesis, act under thermodynamic control ${ }^{9}$. Conse-

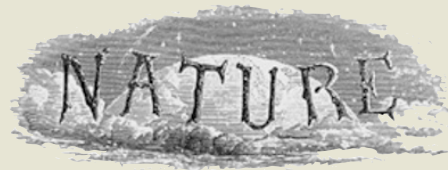

50 Years Ago

A technique has been used with limited success to obtain simultaneous measurement of cosmic radiation at two different altitudes. The method consists of suspending two packets of nuclear emulsion plates from the one balloon, while maintaining a constant vertical separation of $10,000-27,000 \mathrm{ft}$. between the packets ... in this way the two packets do not separate in latitude and longitude-a factor which enters if two separate independent balloons are flown.

This has been achieved by carrying aloft a cone of nylon string which was allowed to unwind at a predetermined height, leaving one packet of plates suspended at the balloon while the other fell at the end of the string ... As the alarm rings, the alarm winder releases the key ... holding the lower packet and target, which then fall away freely, unwinding the string in the process. Twenty thousand feet of string unwinds in approximately $10 \mathrm{~min}$. From Nature 20 July 1963

100 Years Ago

The Potato: A Compilation of Information from Every Available Source. By E. H. Grubb and W. S. Guilford.

There are men who, having attained to wealth and fame by the agency of some humble instrument, basely repudiate and kick over the ladder by which they have risen. Not so the authors of the first book on our list. The potato has "made" them, and in return they proceed to "make" the potato ... the authors are so evidently enthusiastic, and discourse so eloquently on the merits of their subject, that we are carried along with them, and forget that, after all, they are only talking about potatoes, and not about alpine plants or roses.

From Nature 17 July 1913 